\title{
Changes in the mineralogy of a cultivated marsh soil caused by simulated weathering
}

\author{
P. DE ARAMBARRI \& O. TALIBUDEEN \\ Centro de Edafologia y Biologia Aplicada del Cuarto, Apartado 1052, Sevilla, Spain
}

\begin{abstract}
SUMMARY
Differential heats and isotherms for $\mathrm{K}-\mathrm{Ca}$ exchange and $\mathrm{CEC}$ values show that simulated weathering by grinding and NaTPB treatment of the coarse clay fraction of a rice-growing marsh soil exposed vermiculitic layers to reaction with ions in solution, and also created more montmorillonitic layers and uncharged clay. Calcium selectivity was also increased, especially at $\mathrm{K}$ saturations $>50 \%$. Changes in the CEC values of the fine clay, fine silt and coarse silt by such treatment, compared with that in the coarse clay fraction, were used to predict changes in the layer charges of their component phyllosilicates.
\end{abstract}

\section{INTRODUCTION}

Some 4000 a ago the River Guadalquivir in Andalusia, Spain, discharged into a saline lake which was isolated from the Atlantic Ocean by a littoral cord of dunes. The saline lake bottom was formed by a very thick layer of Lower Miocene-Upper Pliocene impermeable blue marls (Viguier, 1977). The runoff of the Guadalquivir valley filled the lake with different, mostly non-swelling clays (Moreno et al., 1978), and $2000 \mathrm{~km}^{2}$ of marshes developed through which the river cut its estuary. The marshes became drier and a calco-sodic gley, or takinic solonchak, type of soil developed on the fluvio-marine sediments. About 40000 ha of this soil have been reclaimed (Moreno et al., 1981) and are used to grow very high yields of rice only (medium yield $6 \mathrm{tha}^{-1}$ ) with very specialized agricultural techniques. The rice is sown and treated with pesticides from the air, but the soil is fertilized, the rice harvested and the wet straw ploughed deeply into the soil using very heavy machinery. The heavy machinery and the use of ammonium compounds as fertilizers can enhance the loss of soil potassium and facilitate the development of swelling clays with consequent damage to the physical properties of the soil.

In previous work (Navarro et al., 1984), we found that these soils, when ground, increased their labile $\mathrm{K}$ content and showed changes in their X-ray powder diagrams. The effects of treatments designed to simulate weathering, the use of heavy machinery and the effects of $\mathrm{K}$ uptake by the rice crop on the nature of the clay in this soil have been investigated by a microcalorimetric 'finger print' method (Talibudeen \& Goulding, 1983a, $b$; Talibudeen, 1984).

\section{MATERIALS AND METHODS}

A range of particle size fractions was separated from the soil. These were ground and their potassium extracted with sodium tetraphenylboron (NaTPB) to simulate and accelerate weathering and $\mathrm{K}$ uptake. NaTPB was added in excess to the soil fractions and the mixtures ground for $60 \mathrm{~min}$ in a ball mill at 60 r.p.m. The KTPB thus produced and the unreacted NATPB were washed out with $0.1 \mathrm{M} \mathrm{CaCl}_{2}$ at $\mathrm{pH} 7$ until the clay was Ca saturated and the X-ray diffraction (XRD) peak of NaTPB had disappeared. The soil fraction was then rinsed with alcohol and acetone, and air-dried.

The cation exchange capacities (CEC) of the untreated and treated samples was determined by $\mathrm{M} \mathrm{NH}_{4} \mathrm{NO}_{3}$ and $0.1 \mathrm{M} \mathrm{MgCl}_{2}$ extraction, and $\mathrm{Ca}$ and $\mathrm{K}$ analyses of the solution and solid phases. The coarse clay $(0.2-2.0 \mu \mathrm{m})$ were examined at $20^{\circ} \mathrm{C}$ by the Gaines and Thomas thermodynamic 
treatment of $\mathrm{K}-\mathrm{Ca}$ exchange isotherms and by the microcalorimetry of $\mathrm{K}-\mathrm{Ca}$ exchange (Talibudeen \& Goulding, 1983a,b; Talibudeen, 1984). Briefly, the Ca saturated samples were brought to equilibrium with $\mathrm{KCl}+\mathrm{CaCl}_{2}$ solutions of contrasting composition and the solution and clay phases analysed for $\mathrm{K}$ and $\mathrm{Ca}$ contents, and for exchangeable $\mathrm{K}$ and $\mathrm{Ca}$, respectively, to give $\mathrm{K}-\mathrm{Ca}$ exchange isotherms. In parallel experiments, the Ca-saturated samples were treated with increasing amounts of $\mathrm{KCl}$ solution, and the heats evolved measured in a LKB microcalorimeter.

\section{RESULTS AND DISCUSSION}

\section{$X$-ray diffraction}

$\mathrm{XRD}$ analysis examines the mineralogical composition of the matrix of a sample. The $\mathrm{K}-\mathrm{Ca}$ exchange properties investigated in this work deal with the redistribution of layer charge in $2: 1$ phyllosilicates on grinding and NaTPB treatment, which may not necessarily correspond with XRD data. A semi-quantitative XRD analysis of the 0.2-2.0 $\mu \mathrm{m}$ fraction before and after treatment showed that the ratios of illite: smectite : kaolinite changed from $1: 0.06: 0.33$ to $1: 0.21: 0.20$, suggesting that illitic mica 'degraded' to smectite, and kaolinite to amorphous oxides. It was most likely that some of the original smectite also degraded like the kaolinite, which was supported by the fact that the CEC of the $<0.2 \mu \mathrm{m}$ fraction (containing only smectite and amorphous oxides) decreased on treatment- - see below and Table 3.

The percentage increase in CEC of the coarse clay fraction $(0.2-2.0 \mu \mathrm{m})$ brought about by treatment was about the same at any point on the $\mathrm{K}-\mathrm{Ca}$ isotherm, whether determined by $\mathrm{M} \mathrm{NH}_{4} \mathrm{NO}_{3}$ extraction $(69 \%$ ), or by exchangeable $\mathrm{Ca}$ in the Ca-saturated clay extracted with $0.1 \mathrm{M} \mathrm{MgCl}_{2}(61 \%)$. This was caused by the treatment opening up negatively charged layers in the clay to make contact with ions in solution.

\section{Thermodynamic measurements}

Preference for $\mathrm{K}$, as expressed by the standard free energy $\left(\Delta G_{0}\right)$ (Table 1), was decreased after treatment. This implied that prolonged treatment might eventually convert this clay into one that had an overall preference for Ca over $\mathrm{K}$. The standard enthalpy $\left(\Delta H_{0}\right)$ values were obtained by extrapolating the integral enthalpy $v \mathrm{~K}$ saturation curve to $100 \% \mathrm{~K}$ saturation, and showed that $\mathrm{K}$ binding strength was greatly increased by treatment but not sufficiently to increase $\mathrm{K}$ preference. The more negative standard entropy value (expressed in $T \Delta S$ units) after treatment showed that the disorder in the arrangement of charged layers and the counter ions was greatly increased. This decreased $\mathrm{K}$ preference more than the increase caused by the increased binding strength. The contribution of the hydration of interlayer $\mathrm{K}$ and $\mathrm{Ca}$ ions to the enthalpic and entropic components of the free energy of K-Ca exchange has already been discussed in detail (Deist \& Talibudeen, 1967; Goulding \& Talibudeen, 1980, 1984; Talibudeen \& Goulding, 1983a).

From 0 to $25 \% \mathrm{~K}$ saturation, the values of the selectivity coefficient, In $K_{\mathrm{c}}$ (where $K_{\mathrm{c}}$ is the equilibrium quotient for the reaction Ca-soil $+2 \mathrm{~K}^{+} \rightleftharpoons 2 \mathrm{~K}$-soil $+\mathrm{Ca}^{2+}$; Deist \& Talibudeen, 1967), were greater, showing higher $\mathrm{K}$ selectivity for the treated clay than for the untreated sample; this reversed to lower $\mathrm{K}$ selectivity at $\mathrm{K}$ saturations $\geqslant 55 \%$ (Table 1 ). The curve of $\ln K_{\mathrm{c}}$ against $\mathrm{K} \%$ saturation showed a minor inflexion at about $25 \% \mathrm{~K}$ saturation, indicating a change in layer charge in the untreated clay involved in the $\mathrm{K}-\mathrm{Ca}$ exchange, whereas $\ln K_{\mathrm{c}}$ decreased smoothly with $\mathrm{K}$ saturation in the treated sample; this suggested a change in the distribution of layer charge induced by treatment.

\section{Adsorbed ion activity coefficients}

The adsorbed ion activity coefficients, or $f$ values, express the 'freeness' of the ion adsorbed on the clay surface (relative to that at $100 \%$ saturation with that ion) to leave the surface and react with ions in the equilibrating solution. Although at zero $\mathrm{K}$ saturation $f_{\mathrm{K}}$ values were the same for both samples, the untreated clay showed a maximum near $35 \% \mathrm{~K}$ saturation (Table 1 ), indicating a greater lability of $\mathrm{K}$ ions than that at $100 \%$ saturation. This did not occur with the treated clay, suggesting that the treatment changed the nature of some of the charged layers. The $f_{\mathrm{K}}$ values for 
Table 1. Ca-K exchange isotherms of the coarse clay fraction $(0.2-2.0 \mu \mathrm{m})$ from the surface soil of the Guadalquivir marshes, before and after grinding and NaTPB treatment

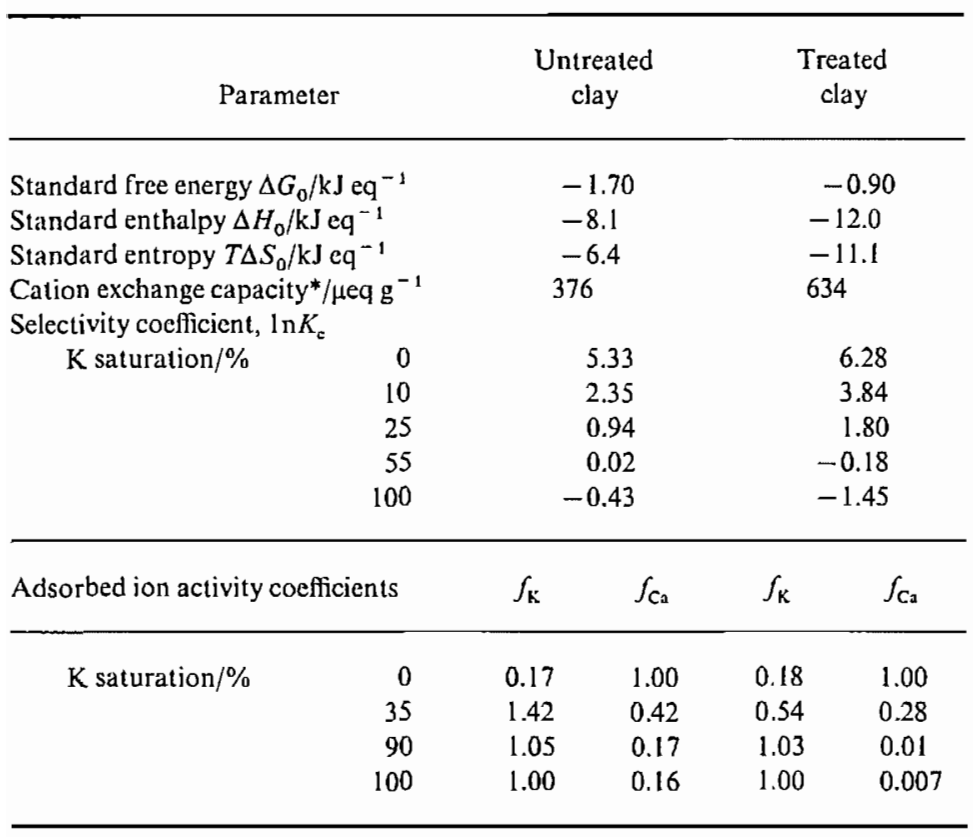

*The CEC values determined by extracting $\mathrm{Ca}$ from the $\mathrm{Ca}$-saturated clay with $0.1 \mathrm{M} \mathrm{MgCl}_{2}$ were 505 and $810 \mu \mathrm{eq} \mathrm{g}^{-1}$.

Table 2. Results of microcalorimetry of $\mathrm{Ca}-\mathrm{K}$ exchange of the coarse clay fraction $(0.2-2.0 \mu \mathrm{m})$ from Guadalquivir marshes, before and after grinding and NaTPB treatment

\begin{tabular}{|c|c|c|c|}
\hline \multicolumn{2}{|c|}{ Determination } & $\begin{array}{l}\text { Untreated } \\
\text { clay }\end{array}$ & $\begin{array}{l}\text { Treated } \\
\text { clay }\end{array}$ \\
\hline \multicolumn{4}{|c|}{$\mathrm{d}(\Delta H) / \mathrm{kJ} \mathrm{eq}^{-1}$} \\
\hline $\mathrm{d} x_{k} \quad K$ saturation/\% & $\begin{array}{r}0-22 \\
23-52 \\
53-57\end{array}$ & $\begin{array}{r}-15.0 \\
-7.7 \\
-7.1\end{array}$ & $\begin{array}{c}-14.8 \\
\text { for } 0-45 \%\end{array}$ \\
\hline \multicolumn{4}{|c|}{ Mineralogical composition $* \% \mathrm{w} / \mathrm{w}$} \\
\hline Vermiculitic mica & & 3.4 & 11.6 \\
\hline Montmorillonite & & 22.6 & 26.8 \\
\hline Uncharged minera & oy difference & 74.0 & 61.6 \\
\hline
\end{tabular}

*Calculated from the differential heats 'spectrum', assigning layer charges of 2460 and $1300 \mu \mathrm{eq} \mathrm{g}^{-1}$ to vermiculitic mica and montmorillonite, respectively (Talibudeen \& Goulding, 1983a,b). 
both samples decreased smoothly from the standard state value of 1.0 at zero $\mathrm{K}$ saturation to much lower values at $100 \% \mathrm{~K}$ saturation, but this decrease was much more for the treated sample; indicating its greater $\mathrm{Ca}$ selectivity as $\mathrm{K}$ saturation increased.

\section{Differential heat measurements}

These measurements of $\mathrm{d} \Delta H / \mathrm{d} x_{\mathrm{K}}$, where $x_{\mathrm{K}}$ is the fractional $\mathrm{K}$ saturation, are given in Table 2; they were quite independent of the exchange isotherm studies, and the mineralogical compositions were derived from them. It was reassuring that they confirmed the conclusions from the analysis of the results of the $\mathrm{K}-\mathrm{Ca}$ exchange isotherms. The differential heat attributed to vermiculitic mica (Talibudeen \& Goulding, $1983 a, b$ ) indicated that the untreated sample contained $3.4 \%$ of this mineral, which increased to $11.6 \%$ on treatment, creating and exposing charged layers to make contact with ions in solution, and contributing most to the increase in CEC (Table 1). The remaining negative charge in the untreated clay was attributed to 'pure' montmorillonite layers, at least up to $57 \% \mathrm{~K}$ saturation, based on differential heats of 7.7 and $7.1 \mathrm{~kJ} \mathrm{eq}^{-1}$. As this is the phyllosilicate with the smallest layer charge, the remaining $43 \%$ of the CEC can be attributed to it also. After allowing for the weight percentages of vermiculitic mica and montmorillonite, the remaining $74 \%$ of mass had to be ascribed to uncharged 'pure' 1:1 phyllosilicates (Talibudeen \& Goulding, 1983a, b), uncharged 2:1 phyllosilicates and oxides. Thus, the artificial weathering treatment increased the vermiculitic and montmorillonitic layers (with about half the layer charge of the vermiculitic layers) exposed to contact with the solution phase. The montmorillonitic layers were presumably increased by the degradation of the vermiculitic layers.

Table 3. Changes in the CEC of particle size fractions of the soil caused by the grinding and NaTPB treatment

\begin{tabular}{cccc}
\hline & & \multicolumn{2}{c}{ Cation exchange capacity } \\
\cline { 3 - 4 } $\begin{array}{c}\text { Particle } \\
\text { size } \\
(\mu \mathrm{m})\end{array}$ & $\begin{array}{c}\text { Percentage of } \\
\text { original soil }\end{array}$ & $\begin{array}{c}\text { Untreated } \\
\left(\mu \mathrm{eq} \mathrm{g}^{-1} \text { of fraction) }\right.\end{array}$ & $\begin{array}{c}\text { Treated } \\
\left(\mu \mathrm{eq} \mathrm{g} \mathrm{g}^{-1} \text { of fraction) }\right.\end{array}$ \\
\hline$<0.2$ & 22.1 & 755 & 645 \\
$0.2-2.0$ & 43.2 & 505 & 805 \\
$2.0-5.0$ & 31.1 & 370 & 810 \\
$5.0-20.0$ & 2.9 & 240 & 293 \\
\hline
\end{tabular}

Such detailed examination could not be extended to the other soil fractions, but the increase in CEC (Table 3) of the $2-5 \mu \mathrm{m}$ fraction $(220 \%)$ and the $5-20 \mu \mathrm{m}$ fraction $(22 \%)$ after grinding and $\mathrm{NaTPB}$ treatments suggested that the conclusions reached from the detailed work on the $0.2-2.0 \mu \mathrm{m}$ fraction (CEC increase 60\%) must apply to these coarser fractions. The CEC of the fine clay $(<0.2 \mu \mathrm{m})$ fraction decreased by $15 \%$ after treatment, indicating that the untreated sample's charged layers consisted entirely of pure montmorillonite layers-compare the analysis of $<0.2 \mu \mathrm{m}$ Wyoming bentonite in Talibudeen \& Goulding (1983a). These layers must have degraded to uncharged amorphous layers by the grinding and NaTPB treatment-hence the loss in CEC.

If such treatment simulated weathering by natural processes and cultivation, then these results suggest that (a) the finest clay fraction weathers least, creating more amorphous oxides and kaolinites in the process, (b) the coarse clay and fine silt fractions weather most: since the latter contain the largest amounts of micas and interstratified $2: 1$ phyllosilicates, the weathering treatments exposed more charged layers to the solution phase, and (c) the coarse silt fraction behaves similarly, though to a much lesser extent, since its micaceous minerals consist of larger and more crystalline particles than those in the smaller particle size fractions. 


\section{REFERENCES}

Deist, J. \& TAlibudeEN, O. 1967. Thermodynamics of $\mathrm{K}-\mathrm{Ca}$ ion exchange in soils. Journal of Soil Science $18,138-148$.

Goulding, K. W. T.\& TAlibudeen, O. 1980. Heterogeneity of cation-exchange sites for $\mathrm{K}-\mathrm{Ca}$ exch ange in aluminosilicates. Journal of Colloid and Interface Science 78, 15-24.

Goulding, K.W.T.\& TAlidudeen, O. 1984. Thermodynamics of $\mathrm{K}-\mathrm{Ca}$ exchange in soils. I. Effects of potassium and organic matter residues in soils from the Broadbalk and Saxmundham Rotation I Experiments. Journal of Soil Science 35, 397-408.

Moreno, F., Martin, J. \& Arrue, J.L. 1978. Clay minerals and physical fertility improvement in some representative SW Spain soils. Proceedings of the International Symposium on Soil Fertility Improvement and Clay Minerals, Prague, Vol. II, pp. 271-280.

Moreno, F., Martin, J. \& Mudarra, J.L. 1981 . A soil sequence in the natural and reclaimed marshes of the Guadalquivir River, Sevilla, Spain. Catena 8, 201-221.
Navarro, J., Arambarri, P. de \& Madrid, L. 1984. Efecto de la molienda y la fertilización nitrogenada sobre la liberación de potasio de un suelo de la marisma del Guadalquivir. Proceedings $X X$ Real Societé España Química, Castellon, pp. 10-14.

TALlBudeEN, O. 1984. Charge heterogeneity and the calorimetry of $\mathrm{K}-\mathrm{Ca}$ exchange adsorption in clays and soils. Adsorption Science and Technology 1 , 235-246.

TalibudeEn, O. \& Goulding, K.W.T. 1983a. Charge heterogeneity in the Smectites. Clays and Clay Minerals 31, 37-42.

Talibudeen, O. \& Goulding, K.W.T. $1983 b$. Apparent charge heterogeneity in the kaolins in relation to their 2:1 phyllosilicate content. Clays and Clay Minerals 31, 137-142.

Viguier, C. 1977. Les grands traits de la tectonique du bassin neogene du Guadalquivir. Boletin Geologique Minerale 88, 39-44.

(Received 29 September 1985) 